\title{
FEATURES OF THE HUMAN LIFE-WORLD STABILITY OF FUTURE DOCTORS WHO ARE CHARACTERIZED BY PSYCHOLOGICAL HEALTH
}

\author{
Olga V. Petryaeva ${ }^{2}$, Irina O. Loginova ${ }^{1,2}$, Irina O. Kononenko ${ }^{1}, \&$ Nina N. Vishnjakova ${ }^{1}$ \\ ${ }^{I}$ Professor V.F. Voyno-Yasenetsky Krasnoyarsk State Medical University (Russia) \\ ${ }^{2}$ Federal State-Financed Institution Federal Siberian Research Clinical Centre under the Federal \\ Medical Biological Agency (Russia)
}

\begin{abstract}
Staying at the peak of professional success in medical is possible only for a doctor who is characterized by psychological health. The human life-world stability is contributed to success of the life self-fulfillment and transference of abilities inherent in him (human) into reality. The study sample is represented by 354 future doctors. Of these, 154 future doctors were characterized by psychological health.

Qualitative analysis showed that future doctors who are characterized by psychological health are more inclined to analyze their own life deficits "here and now". Often, such an analysis culminated in the realization of the possibility of approaching problems and difficulties, finding a different meaning. Usually assessed as "negative" or "stressful" events during the analysis were reformatted as events of a new experience. They are the basis for expanding the behavioral repertoire.

It has been established that a high degree of human life-world stability and its constructive nature are the psychological conditions for the optimal combination of processes to achievement consistently high performances and maintain psychological health by future doctors.
\end{abstract}

Keywords: Human life-world stability, life self-fulfillment, psychological health, high performances, future doctors.

\section{Introduction}

Staying at the peak of professional success in medical is possible only for a doctor who is characterized by psychological health. Maintaining psychological health doctors need to implement a whole range of measures. An important role in this complex is given to psychotechnologies aimed at improving the life-world stability of future doctors.

When training future doctors, the opportunities for achievements that are determined by psychological health are often not taken into account. The phenomenon of "human life-world stability" is also not taken into account. However the human life-world stability is considered in psychology as an essential indicator of the success of the life self-fulfillment. It can be taken into account in the organization of training future doctors.

\section{Design}

The study sample is represented by 354 future doctors. Of these, 154 future doctors were characterized by psychological health.

At the first stage of the study, a sample of athletes was analyzed for the preservation of psychological health (Table 1).

Table 1. The distribution of athletes in psychological health groups.

\begin{tabular}{ccc} 
Psychological health group & Men (absolute number, \%) & Women (absolute number, \%) \\
\hline I & $54(23,7 \%)$ & $20(15,7 \%)$ \\
\hline II & $54(23,7 \%)$ & $26(20,4 \%)$ \\
\hline IIIA & $8(3,5 \%)$ & $8(6,3 \%)$ \\
\hline IIIБ & $103(45,6 \%)$ & $64(50,3 \%)$ \\
\hline IIIA, Б & $8(3,5 \%)$ & $9(7,3 \%)$ \\
\hline
\end{tabular}


The table shows the psychological health groups that are distributed as follows:

Group I - a high level of psychological health;

Group II - conditionally healthy - have a clear predisposition (risk factors) to reduce mental adaptation in the absence of special and timely preventive measures and strengthen psychological health;

Group IIIA - impaired psychological health, due to severe neurotic symptoms;

Group IIIB - impaired psychological health due to a decrease in the functional state of the ANS and / or CNS

Group IIIA, B - impaired psychological health due to mixed symptoms.

At the main stage of the study, the correlation of indicators of psychological health and the human life-world stability of future doctors was carried out.

\section{Objectives}

The purpose of this study is to research of the human life-world stability of future doctors who are characterized by psychological health.

The main objectives of the research are:

1) Investigate the features of the psychological health of future doctors;

2) To study the specifics of the life-world stability of future doctors who are characterized by psychological health in contrast to future doctors with impaired psychological health.

\section{Methods}

At the preparatory investigation stage, the assessment of psychological health was carried out by means of the following methods:

- structured standard interview;

- psychological testing using hardware and software systems.

The integral indicator that characterized the psychological state of the future doctors, according to the results of the survey, was calculated. Then the final conclusion about psychological health was formed.

The method "Investigation of the Human Life-World Stability" (Loginova, 2012) was used as the general research tool, which allows to study the features of the human life-world stability in the process of real-life activity. This method is aimed at studying the features of the human life organization and allows revealing the manifestations of the life stability (constructive, unconstructive, and stagnant).

Mathematical processing of the obtained results was carried out with use of the SPSS Statistics 21 software packaging.

\section{Discussion}

All results of the two groups of respondents obtained by means of the method "Investigation of the Human Life-World Stability" were systematized in accordance with the instruction and are presented in Table 2.

Table 2. Results of the human life-world stability of psychological health groups.

\begin{tabular}{|c|c|c|}
\hline Options & Psychological health group & Groups with impaired psychological health \\
\hline \multirow{3}{*}{$\begin{array}{l}\text { Temporal tendency } \\
\text { of events }\end{array}$} & The present - the future $60 \%$ & The present $30 \%$ \\
\hline & The past - the present - the future $40 \%$ & The past $40 \%$ \\
\hline & & The past - the present $30 \%$ \\
\hline \multirow[t]{3}{*}{ The ratio of verbs } & The present - the future $60 \%$ & The present $40 \%$ \\
\hline & The past - the present - the future $40 \%$ & The past $40 \%$ \\
\hline & & The past - the present $20 \%$ \\
\hline \multirow{3}{*}{$\begin{array}{l}\text { Criterion for the } \\
\text { described events } \\
\text { content selecting }\end{array}$} & Chronotopic $30 \%$ & Chronotopic $20 \%$ \\
\hline & Topological 60\% & Topological 20\% \\
\hline & Biographical $10 \%$ & Biographical $60 \%$ \\
\hline \multirow{3}{*}{$\begin{array}{l}\text { General emotional } \\
\text { background of } \\
\text { events }\end{array}$} & Positive $60 \%$ & Positive $30 \%$ \\
\hline & Neutral 30\% & Neutral $40 \%$ \\
\hline & Negative $10 \%$ & Negative $30 \%$ \\
\hline \multirow[t]{4}{*}{$\begin{array}{l}\text { The meaning of the } \\
\text { described life events }\end{array}$} & $\begin{array}{l}\text { The overall direction of the development } \\
\text { line is conserved } 50 \%\end{array}$ & $\begin{array}{l}\text { The overall direction of the development line } \\
\text { is conserved } 20 \%\end{array}$ \\
\hline & $\begin{array}{l}\text { General orientation of the development line } \\
\text { is not withheld } 30 \%\end{array}$ & $\begin{array}{l}\text { General orientation of the development line is } \\
\text { not withheld } 30 \%\end{array}$ \\
\hline & The beginning of the development line & Center of the development line $20 \%$ \\
\hline & $20 \%$ & Completion of the development line $30 \%$ \\
\hline
\end{tabular}




\begin{tabular}{lll}
\hline Attitude to events & Value $60 \%$ & Value $15 \%$ \\
& Responsible 20\% & Responsible 5\% \\
& Rational $20 \%$ & Rational $80 \%$ \\
\hline Continuity of & Retained $75 \%$ & Retained $5 \%$ \\
personal history & Situationally $20 \%$ & Situationally $30 \%$ \\
& Missing $5 \%$ & Missing $65 \%$ \\
\hline Author reflexive & Holistic reflexive position $60 \%$ & Holistic reflexive position $10 \%$ \\
position & Situational reflexive attitude $25 \%$ & Situational reflexive attitude $30 \%$ \\
& Absence of a reflexive relation $10 \%$ & Absence of a reflexive relation $60 \%$ \\
\hline
\end{tabular}

In $50.7 \%$ of psychologically healthy future doctors of the highest qualification (men and women), the human life-world stability was 67.3 points. This means that there is a tendency towards the manifestation of a constructive nature of the human life-world stability. It contributes to the preservation of health, personal growth and creativity. In the life of such future doctors, the presence of prospects for further movement and a resource for success is revealed.

In $33.8 \%$ of psychologically healthy future doctors (men and women), the human life-world stability was 46.8 points. This means that there is a tendency towards the manifestation of a non-constructive nature of the human life-world stability. It reduces the productivity and optimality of human life and marks the lack of a resource (own potential, environmental conditions) for success.

In $15.5 \%$ of psychologically healthy future doctors (men and women), the human life-world stability was 36.4 points. This means that there is a tendency towards the manifestation of a stagnant nature of the human life-world stability.

Qualitative analysis showed that future doctors who are characterized by psychological health are more inclined to analyze their own life deficits "here and now". Often, such an analysis culminated in the realization of the possibility of approaching problems and difficulties, finding a different meaning.

Usually assessed as "negative" or "stressful" events (ineffectiveness, mistake, conflicts, status changes in the team) during the analysis were reformatted as events of a new experience.

They are the basis for expanding the behavioral repertoire. The presence of this trend suggests that in a similar "problem" situation, these future doctors will demonstrate increasingly effective patterns of cognitive and affective response, more adapted behavioral reactions.

\section{Conclusions}

We believe that the our research has an indicates its suitability for use in medical practice (Sirri, Fava, 2013) and a direct access to the research of the human being that is understood as the expansion of the possibilities since it considers the problems of emerging, existing, transformation, development and self-development of a human being in their unity. In the framework of these research, there is a possibility to consider the issues of individual life strategies defining the direction vector and content of a human being life that are in their turn are defining in respect of the selected strategy for the living potential realization (Deci \& Ryan, 2000). In the process of life targets realization that seemed ended, we reveal their "transition", "temporal" nature that reveals the prospects of movement to the next objective. As such, to understand a human being as the product of the human being oneself, his life, means the possibility to understand the human being itself that is the most mysterious object in the world. This is why in each single deed, action, act of vital activity and life creation a human being "feels oneself a part of this powerful life impulse" (Blauberg, 2003), personifying in the process of life the creativity, endless development, unperceivable variety that is the infinite number of freedom degrees that defines unlimited possibilities of a human being.

It has been established that a high degree of human life-world stability and its constructive nature are the psychological conditions for the optimal combination of processes to achievement consistently high sports performances and maintain psychological health by future doctors.

\section{References}

Blauberg, I.I. (2003). Henri Bergson. Moscow: Progress-Traditsiya.

Deci,E., \& Ryan, R. (1986). The dynamics of self-determination in personality and development. Self-related cognitions in anxiety and motivation. Hillsdale. 171-194.

Loginova, I.O. (2012). Research of stability of the vital world of the person: technique and psychometric characteristics. Psychological Science and Education, 3, 18-28.

Sirri, L., Fava, G.A. (2013). Diagnostic criteria for psychosomatic research and somatic symptom disorders. Int Rev Psychiatry. 25(1), 19-30. 